\title{
Tetracaine $0.5 \%$ eyedrops with or without lidocaine $2 \%$ gel in topical anesthesia for cataract surgery
}

This article was published in the following Dove Press journal:

Clinical Ophthalmology

20 August 2010

Number of times this article has been viewed

\author{
Anthoula T Tsoumani ${ }^{1,2}$ \\ loannis C Asproudis' \\ Dimitrios Damigos ${ }^{2}$ \\ 'Department of Ophthalmology \\ University Hospital of Ioannina, \\ ${ }^{2}$ Department of Medical Psychology, \\ Postgraduate Course of "Pain \\ Management", University of Ioannina, \\ Greece
}

Background and objective: To evaluate the level of pain during phacoemulsification and foldable intraocular lens implantation under instillation of tetracaine $0.5 \%$ eyedrops versus a combination of lidocaine $2 \%$ gel and instillation of tetracaine eyedrops.

Methods: This prospective, randomized, controlled study included 51 patients undergoing phacoemulsification under topical anesthesia. They were randomized into two groups based on the topical anesthetic method they were to receive. Preoperatively all patients were asked to answer a questionnaire. One hour postoperatively, they were asked to grade their intraoperative and postoperative pain on a visual analog scale from 0 to 10 .

Results: There were no statistically significant differences between the two methods of anesthesia. Gender and the presence of relatives or friends were independent factors playing a significant role in pain sensitivity.

Conclusions: The combination of lidocaine $2 \%$ gel and tetracaine eyedrops does not have a better analgesic result than a single instillation of tetracaine $0.5 \%$ eyedrops.

Keywords: ophthalmic pain, cataract, phacoemulsification, tetracaine eyedrops, lidocaine gel, topical anesthesia

\section{Introduction}

Cataract remains the most common cause of blindness in the developing world. ${ }^{1}$ Phacoemulsification cataract surgery is one of the most commonly performed elective surgical procedures in Europe and the US. More than $99 \%$ of cataract operations in the UK are now treated using this technique. ${ }^{2}$ It is anticipated that a further 225,000 new cases of visually significant cataract will be treated every year in the UK. In the US, more than one million cataract operations are performed per year. ${ }^{3}$ More than 3000 of these procedures are performed every year using phacoemulsification at the University Hospital of Ioannina in Greece.

Because cataract surgery has developed into a rapid turnover day case procedure, the options for anesthesia have also evolved. There are currently several options for cataract surgery anesthesia. ${ }^{4}$ Topical anesthesia for phacoemulsification was first described by Fichman in $1992 .^{5}$ Topical anesthesia is widely accepted in cataract procedures, and has become the first choice in most cases of planned routine cataract surgery. ${ }^{6,7}$ This has found wide acceptance, especially in the US, where it is used by $61 \%$ of cataract surgeons (up from $8 \%$ in $1995,51 \%$ in 2000 ) particularly those undertaking high-volume surgery. ${ }^{8}$ This type of anesthesia does not have the injectionrelated complications of retrobulbar or peribulbar anesthesia, reduces surgical costs, and increases patient satisfaction. ${ }^{9,10}$ However, careful patient selection is important,
Correspondence:Anthoula T Tsouman Thriassio Hospital, Ophthalmology Department, Gennimata Avenue, Magoula Attikis, Greece

Tel +302105534720

Fax +302105534720

Email anthitsoumani@yahoo.gr 
and the technique may not be suitable for uncooperative and anxious patients. Operating under topical anesthesia also requires an experienced and highly skilled surgeon. ${ }^{11}$

Topical anesthetics can be used as drops, gel, or intracameral injection in cataract surgery. The most frequently used agent for topical anesthesia is tetracaine $0.5 \%$ eyedrops which are safe and effective in most cases. ${ }^{10}$ Some patients report intraoperative and/or postoperative pain and discomfort after instillation of tetracaine eyedrops as topical anesthesia. ${ }^{12,13}$

The clinical efficacy of lidocaine $2 \%$ gel has been evaluated in different studies, all of which have reported that the gel is safe and provides good pain control in most cases. ${ }^{14,15}$ Gel anesthesia with lidocaine $2 \%$ has shown higher intracameral levels of lidocaine, better analgesia, better patient cooperation, and less need for intraoperative analgesia than lidocaine $4 \%$ topical drops. ${ }^{16}$

In this study, we compared and evaluated the efficacy of tetracaine $0.5 \%$ eyedrops and the combination of lidocaine $2 \%$ gel application and instillation of tetracaine $0.5 \%$ eyedrops as methods of topical anesthesia during phacoemulsification and one hour postoperatively.

\section{Methods}

Approval for the study was obtained from the hospital ethics committee. All patients received a thorough explanation of the study design and aim, and signed an informed consent.

This prospective, controlled, randomized, single-center, clinical trial included 51 patients scheduled for planned routine cataract surgery, ie, phacoemulsification with intraocular lens implantation, from May 2008 to July 2008. The exclusion criteria were Alzheimer's disease, psychologic and mental disorders, reported allergy to topical anesthetic agent, and the use of analgesic medications in the three days before surgery.

Preoperatively, all patients received a routine ophthalmic checkup consisting of visual acuity, anterior chamber and fundus examination, measurement of intraocular pressure, and biometry for the selection of the correct lens implant. Patients were randomly allocated to one of two groups, using sealed number envelopes that contained the name of the anesthetic to be administered. One group received $0.5 \mathrm{~cm}$ lidocaine $2 \%$ gel plus one drop of tetracaine $0.5 \%$, while the other group received only one drop of tetracaine $0.5 \%$. Starting 15 minutes prior to surgery, anesthetics were applied every five minutes in the conjunctival fornices. Both patients and the surgical assistant who collected the data were blinded to which anesthetic agent was given. No patient had simultaneous bilateral surgery. All patients received a tablet of haloperidol orally one hour before the surgery. No patient received preoperative or intraoperative sedation.

All patients had routine monitoring of arterial oxygen saturation, electrocardiography, and blood pressure, as well as intravenous access fashioned before the administration of anesthetic. Mydriasis was obtained preoperatively using phenylephrine hydrochloride $10 \%$ and tropicamide $0.5 \%$. Phacoemulsifications were performed by one experienced surgeon using the same technique of temporal and clear corneal incision. Foldable intraocular lenses were implanted. If the patient reported marked pain or discomfort during the surgery, supplemental topical anesthesia of two drops of tetracaine was administered.

Preoperatively, all patients were asked to answer a questionnaire, which was devised specifically for the study in the form of an verbal interview. The aim of this questionnaire was to collect information about factors which could influence the evaluation of pain. All patients were asked about their everyday medications and about any pain-relieving medications that they may occasionally take. We also thought that it could be useful to know if the patients had had any previous experience of cataract surgery, and if they were accompanied to the hospital by friends and/or relatives.

Immediately after the completion of surgery, patients were asked to grade their pain on a visual analog scale (VAS, $0=$ no pain, $10=$ severe unbearable pain) intraoperatively (VAS1) and postoperatively approximately one hour after the surgery (VAS2). The patients were also asked to differentiate the characteristics of pain or discomfort. Data recorded included eye conditions and systemic diseases, age, gender, and whether the patient was escorted to the hospital by friends and relatives. The Student's t-test was used to compare the groups for statistical purposes.

\section{Results}

Fifty-one patients, aged 51-86 years, were included in the study. Twenty-seven patients (53\%) were randomized to receive tetracaine eyedrops and $24(47 \%)$ to receive combined tetracaine eyedrops and lidocaine gel. In our sample, $31 \%$ had had eye surgery in the past. Forty-seven percent of

Table I The statistically important variables correlating with intraoperative pain

\begin{tabular}{lllll}
\hline Parameter & Estimate & $\begin{array}{l}\text { Standard } \\
\text { error }\end{array}$ & \multicolumn{2}{l}{ 95\% confidence interval } \\
\cline { 3 - 5 } & & 0.858 & Lower limit & Upper limit \\
\hline Constant & 3.684 & .959 & 5.408 \\
Gender & -2.557 & 0.567 & -3.698 & -1.417 \\
Company & 1.981 & 0.823 & 0.327 & 3.636 \\
\hline
\end{tabular}


Table 2 Intraoperative pain and postoperative pain for the two methods of anesthesia

\begin{tabular}{llllll}
\hline & Anesthesia & $\mathbf{n}$ & Mean & Standard deviation & Standard error mean \\
\hline Intraoperative pain & Tetracaine eyedrops & 27 & 4.19 & 2.321 & 0.447 \\
& Tetracaine drops + lidocaine gel & 24 & 3.88 & 2.724 & 0.556 \\
Postoperative & Tetracaine eyedrops & 27 & 1.11 & 1.625 & 0.313 \\
pain & Tetracaine drops + lidocaine gel & 24 & 1.58 & 1.666 & 0.340 \\
\hline
\end{tabular}

the patients were taking analgesic medication occasionally for different reasons. No patient in either treatment group reported a pain score of 10 . During surgery, a pain score of 8 was reached by two patients in the tetracaine eyedrops group and by three in the combined tetracaine eyedrops and lidocaine gel group, and supplemental topical anesthesia of two drops of tetracaine was administered in these patients. Five patients in the first group had a pain score of 0 after surgery, as did nine in the second group. However, this difference between the two different methods of anesthesia was not statistically significant (Table 2). The results of the t-test for the comparison of the two techniques of anesthesia are shown in Table 3. The pain score one hour after surgery was $40 \%$ lower than the pain score during phacoemulsification.

Two parameters for which the differences were statistically significant were gender and the presence of relatives or friends at the hospital. Men $(27 / 51,52.9 \%)$ reported less pain than did women in both the treatment groups. It was interesting to note that patients from both groups who were accompanied by friends or relatives $(44 / 51,86.3 \%$ ) reported more pain (Table 1). There were no statistically significant differences between the treatment groups with regard to patient age, education level, eye conditions, systemic diseases, and habitual use of analgesics.

\section{Discussion}

Our results show that both tetracaine $0.5 \%$ eyedrops alone and the combination of tetracaine $0.5 \%$ eyedrops plus lidocaine $2 \%$ gel have good anesthetic properties for topical use in cataract surgery. However, no statistically significant difference in pain scores during surgery or postoperatively was observed between the two groups (Table 1).

Similar results have been reported previously in the literature. Barequet et al also reached the conclusion that lidocaine $2 \%$ was comparable with tetracaine $0.5 \%$ eyedrops in provision of corneal anesthesia. They also found that a single application of one quarter inch of gel gave pain scores equivalent to three doses of tetracaine eyedrops. ${ }^{16}$ Amiel et al compared the anesthetic effect of the two drugs and concluded that their effects were similar. ${ }^{17}$ These studies were limited by the absence of standardization in the quality of pain reported by the patients, because no validated pain assessment tool such as the VAS was used. On the other hand, studies like the one by Irle et a ${ }^{18}$ showed that the effect of instillation of tetracaine $0.5 \%$ eyedrops is better than that of lidocaine $2 \%$ gel application during cataract surgery, but leaving unanswered questions about the ideal method of topical anesthesia.

Interestingly, although the present study does not demonstrate a significant improvement in pain scores by adding lidocaine gel to the usual regimen of tetracaine eye drops, it does show a statistically significant difference in pain sensitivity between men and women. Men reported less pain than women during their cataract surgery and postoperatively. Similar results were previously demonstrated in the Graven-Nielsen study for a difference in pain sensitivity between men and women, as well as a gender-dependent

Table 3 Results of t-test for comparison of the two methods of anesthesia. The difference does not result in a statistically significant result

\begin{tabular}{|c|c|c|c|c|c|c|c|c|c|}
\hline & \multicolumn{2}{|c|}{$\begin{array}{l}\text { Levene's } \\
\text { test } \\
\text { for equality } \\
\text { of variances }\end{array}$} & \multicolumn{7}{|c|}{ t-test for equality of means } \\
\hline & \multirow[t]{2}{*}{$\bar{F}$} & \multirow[t]{2}{*}{ Sig. } & \multirow[t]{2}{*}{$\mathbf{t}$} & \multirow[t]{2}{*}{ df } & \multirow[t]{2}{*}{ Sig. (2-tailed) } & \multirow[t]{2}{*}{$\begin{array}{l}\text { Mean } \\
\text { difference }\end{array}$} & \multirow[t]{2}{*}{$\begin{array}{l}\text { Std. error } \\
\text { difference }\end{array}$} & \multicolumn{2}{|c|}{$\begin{array}{l}95 \% \text { confidence } \\
\text { interval of the } \\
\text { difference }\end{array}$} \\
\hline & & & & & & & & Lower & Upper \\
\hline VASI Equal variance assumed & 0.783 & $0.38 \mathrm{I}$ & 0.439 & 49 & 0.663 & 0.310 & 0.706 & -1.109 & 1.730 \\
\hline Equal variance not assumed & & & 0.435 & 45.505 & 0.666 & 0.310 & 0.713 & -1.126 & 1.746 \\
\hline VAS2 Equal variance assumed & 0.001 & 0.975 & -1.024 & 49 & 0.311 & -0.472 & $0.46 \mathrm{I}$ & -1.399 & 0.455 \\
\hline Equal variance not assumed & & & -1.022 & 47.991 & 0.312 & -0.472 & 0.462 & -1.401 & 0.457 \\
\hline
\end{tabular}


response to pharmacologic interventions, eg, opioids and nonsteroidal anti-inflammatory drugs. ${ }^{19}$

Another outcome of our study concerns the relationship between pain sensitivity and the presence of accompanying friends and/or relatives. Contrary to what one would expect, patients accompanied by relatives or friends reported more pain than patients who came alone to the hospital. A literature review makes similar observations concerning chronic pain, and it seems that family relationships may have an etiologic role in chronic pain. ${ }^{20,21}$

In conclusion, the combination of lidocaine $2 \%$ gel and tetracaine $0.5 \%$ eyedrops does not have a better analgesic effect than a single instillation of tetracaine $0.5 \%$ eyedrops. Tetracaine $0.5 \%$ eyedrops have very good efficacy for pain control during phacoemulsification and postoperatively.

\section{Disclosure}

The authors report no conflicts of interest in this work

\section{References}

1. Klein BE, Lee KE. Incidence of age-related cataract over a 10 year interval: The Beaver Dam Eye Study. Ophthalmology. 2002;109: 2052-2057.

2. Johnston RL, Sparrow JM, Canning CR, et al. Pilot National Electronic Cataract Surgery Survey: I. Method, descriptive, and process features. Eye. 2005;19:788-794.

3. Royal College of Ophthalmologists. Cataract surgery guidelines 2004. London: Royal College of Ophthalmologists; 2005.Available at: http://www.rcophth.ac.uk/docs/publications/publishedguidelines/FinalVersionGuidelinesApril2007Updated.pdf. Accessed May 15, 2008.

4. Ezra DG, Nambiar A, Allan BD. Supplementary intracameral lidocaine for phacoemulsification under topical anaesthesia. A metaanalysis of randomized controlled trials. Ophthalmology. 2008;115(3): 455-463.
5. Fichman RA. Phacoemulsification with posterior chamber IOL (intraocular lens) can be performed with topical anaesthesia. Paper presented at the Symposium on Cataract, IOL, and Refractive Surgery. San Diego, CA; April 1992.

6. Fichman RA. Use of topical anesthesia alone in cataract surgery. J Cataract Refract Surg. 1996;22(5):612-614.

7. Naor J, Slomovic AR. Anesthesia modalities for cataract surgery. Curr Opin Ophthalmol. 2000;11(1):7-11.

8. Learning DV. Practice styles and preferences of ASCRS members 2003 survey. J Cataract Refract Surg. 2004;30(4):892-900.

9. Roman S, Audin F, Ullern M. Topical versus peribulbar anesthesia in cataract surgery. J Cataract Refract Surg. 1996;22(8):1121-1124.

10. Ezra DG, Allan BP. Topical anesthesia alone versus topical anesthesia with intracameral lidocaine for phacoemulsification. Cochrane Database Syst Rev. 2007;3:CD005276.

11. Bellucci R. Anesthesia for cataract surgery. Curr Opin Ophthalmol. 1999;10(1):36-41.

12. Grant RL, Acosta D. Comparative toxicity of tetracaine, proparacaine and cocaine evaluated with primary cultures of rabbit corneal epithelial cells. Exp Eye Res. 1994;58(4):469-478.

13. Jonston RL, Whitefield LA, Giralt J, et al. Topical versus peribulbar anaesthesia without sedation for clear corneal phacoemulsification. J Cataract Refract Surg. 1998;24(3):407-410.

14. Gills JP, Cherchio M, Raanan MG. Unpreserved lidocaine to control discomfort during cataract surgery using topical anesthesia. J Cataract Refract Surg. 1997;23(4):545-550.

15. Assia EI, Pras E, Yehezkel M, et al. Topical anesthesia using lidocaine gel for cataract surgery. J Cataract Refract Surg. 1999;25(5):635-639.

16. Barequet IS, Soriano ES, Green WR, O'Brien TP. Provision of anesthesia with single application of lidocaine $2 \%$ gel. $J$ Cataract Refract Surg. 1999;25(5):626-631.

17. Amiel H, Koch PS. Tetracaine hydrochloride $0.5 \%$ versus lidocaine $2 \%$ jelly as a topical anesthetic agent in cataract surgery: Comparative clinical trial. J Cataract Refract Surg. 2007;33(1):98-100.

18. Irle S, Luckefohr MH, Tho Seeth T. Tetracaine drops versus lidocaine gel for topical anesthesia in cataract surgery. Klin Monatsbl Augenheilkd. 2003;220(9):625-628. https://www.thieme-connect.com/DOI/ DOI? 10.1055/s-2003-42811

19. Graven-Nielsen T, Arendt-Nielsen L. Gender differences in response to pain. Ugeskr Laegef. 2007;6:169(25):2425-2427.

20. Payne B, Norfleet MA. Chronic pain and the family: A review. Pain. 1986;7:26(1):1-22.

21. Turk DC, Flor H, Rudy TE. Pain and families. Etiology, maintenance and psychosocial impact. Pain. 1987;7:30(1):3-27.
Clinical Ophthalmology

\section{Publish your work in this journal}

Clinical Ophthalmology is an international, peer-reviewed journal covering all subspecialties within ophthalmology. Key topics include: Optometry; Visual science; Pharmacology and drug therapy in eye diseases; Basic Sciences; Primary and Secondary eye care; Patient Safety and Quality of Care Improvements. This journal is indexed on Submit your manuscript here: http://www.dovepress.com/clinical-ophthalmology-journal

\section{Dovepress}

PubMed Central and CAS, and is the official journal of The Society of Clinical Ophthalmology (SCO). The manuscript management system is completely online and includes a very quick and fair peer-review system, which is all easy to use. Visit http://www.dovepress.com/ testimonials.php to read real quotes from published authors. 